\title{
Uyghur-Chinese and Han-Chinese differences on social orientation
}

\author{
X. P. Ren $\cdot$ K. W. Lu $\cdot$ M. Tuerdi
}

Accepted: 14 October 2014/Published online: 2 December 2014

(C) Springer-Verlag Berlin Heidelberg 2014

\begin{abstract}
In two studies, the authors predicted and found that Uyghur-Chinese are more independent and interdependent than Han-Chinese in explicit and implicit measurements: (a) Uyghur-Chinese are more independent in explicit beliefs and show strong dispositional bias and express more socially disengaging emotion and more relational mobility. Their independence could partially mediate the relationship between culture and dispositional bias and socially disengaging emotion and relational mobility. (b) At the same time, Uyghur-Chinese are more interdependent in explicit beliefs and show strong situational bias and express more socially engaging emotion and more holistic thinking style. Their interdependence could partially mediate the relationship between culture and situational bias and socially engaging emotion and holism. The results suggest that Uyghur-Chinese may have a unique self-construal pattern different from the eastern-western paradigm.
\end{abstract}

Keywords Independent $\cdot$ Interdependent $\cdot$ Uyghur-Chinese $\cdot$ Han-Chinese

\footnotetext{
X. P. Ren $(\bowtie) \cdot$ K. W. Lu

Key Laboratory of Behavioral Science, Institute of Psychology, Chinese Academy of Sciences, Beijing, China

e-mail: renxp@psych.ac.cn

K. W. Lu

e-mail: lukw@psych.ac.cn

K. W. Lu

University of Chinese Academy of Sciences, Beijing, China

M. Tuerdi

Beijing Normal University, Beijing, China

e-mail: meikereayi@163.com
} 


\section{Introduction}

In the past two decades or so, the independent/interdependent self has been considered an important part of social orientation (Varnum et al. 2010) that influenced many psychological variables, such as perception, attribution, thinking style, memory, motivation and emotion (Nisbett et al. 2001; Zhu et al. 2007). Independent cultures such as those of the USA and England emphasize the individual's inner trait and desire for autonomy and achievement while keeping himself/herself separated from significant others. On the contrary, in interdependent cultures such as those of China and Japan, an individual pays more attention to harmonious relations with significant others while keeping himself/herself interconnected (Kitayama and Uskul 2011; Markus and Kitayama 1991).

Most of the research related to this field were done between western (mostly USA) and eastern (mostly China, Japan, and South Korea) countries, and the finding was that westerners are more independent or individualistic and easterners are more interdependent or collective (Kitayama and Uskul 2011; Triandis 2001). A previous study noted that there is a strong need to expand samples and populations other than eastern and western (Heine 2010; Henrich et al. 2010). Although most of east-Asian, even Chinese has the same Confucius roots that foster interdependent or collective value, there are other ethnics who have different cultural background, for example, Mongolia-Chinese and Uyghur-Chinese (We will introduce them in detail later.). Are they the same or similar to Han-Chinese who make up most of the Chinese sample of Chinese-Western comparative studies in this domain? It is surprising that little research has been done to examine the cultural differences of Han-Chinese and minority ethnics-Chinese and their effect on psychology such as perception and attribution. This is a key issue dealt with in this article. The objective of the article is to explore the independent/interdependent self of Uyghur-Chinese.

\section{Independent/interdependent self}

Independent/interdependent self is becoming an important social orientation in the last two decades which was used to explain many cultural differences, especially in comparison between eastern and western since it was introduced (Kitayama and Uskul 2011; Markus and Kitayama 1991). The independent self differs from interdependent self in many domains. On explicit values and beliefs, independent social orientation endorses uniqueness and being different from others while the interdependent one embraces compliance to group norms and being similar to others. On self-other boundary, independent social orientation views self as bounded and separate from others while the interdependent one sees self as connected and overlapping with significant others. On cognition and perceptions, the independent self will focus his/her attention on foci and will attribute one's behavior to his/her personality and inner character whereas the interdependent self will pay more attention to context and will not make more situational attribution. On well-being, for the independent self, happiness is thought of as a socially disengaging emotion (e.g., pride) and involves seeking positive states of affection 
regulation while for the interdependent one, happiness is a socially engaging emotion (e.g., sense of closeness to others) and involves avoiding negative states. On motivations, the independent self puts self-achievement as his/her primary goal and may or may not maintain good relations with others at the same time. However, the interdependent self strives for harmonious relations with others as his/her primary goal and at the same time, may or may not give up self-achievement (Markus and Kitayama 1991; Varnum et al. 2010).

Independent/interdependent self exists not only in terms of cultural differences but also within regional cultural differences. There are few distal and proximal factors that prove to foster and cultivate independent/interdependent self to explain cultural differences in areas of ecology, industrialization, social-economic status, residential mobility, pathogen susceptibility, and voluntary frontier settlement (Kitayama and Uskul 2011). It is rational have regional difference on social orientation within a nation if these regions are different among those factors. Some research provided a body of evidence for them. For example, people in Hokkaido are more independent than the people in the main islands of Japan (Kitayama et al. 2006); people in Northern Italy are also more independent than those in Southern Italy (Knight and Nisbett 2007); and people in herding communities are more independent than farmers and fishing communities in Turkey (Uskul et al. 2008).

Markus and Kitayama (1991) and others (e.g., Singelis 1994; Triandis 1989) have argued that individuals possess both independent and interdependent selves but that cultural context typically promotes the development of one them more strongly. Being independent from others and unique and being interdependent with others on the other end are basic needs important to people and have been formed through evolution. From the perspective of measurement, especially explicit measurement, the independent self and interdependent self have been often positively or not correlated by Singelis self-construal scales in different cultures (Cross et al. 2011). In this paper, the independent self and the interdependent self are thought of as two variables, but not the opposite polar of one variable.

\section{Uyghur-Chinese and Han-Chinese}

It was implicitly assumed that all Chinese people are generally the same; their subcultural differences were neglected when compared with other culture groups in terms of cultural psychology although not expressed obviously. Most of the Chinese sample in cultural studies is pure Han-Chinese, although this was not emphasized. The population of some minorities such as Uyghur-Chinese is about 5 million which is similar to a few countries such as Norway and Singapore, and such a number should not be neglected (UN Population 2010).

Although Uyghur-Chinese and Han-Chinese have a long history of communication and interaction with each other, Uyghur-Chinese maintain their independence in many fields, such as language, religion, customs and so on, which may have profound effects on their psychological tendency and behavior (Kitayama and Uskul 2011). 


\section{Language}

Language maybe the most pervasive and important factor related to cognitive styles (Nisbett et al. 2001). The Chinese language (most of the time, it is equivalent to HanChinese), which is pictographic, encourages thinking of the world as continuous and interrelated. It is also highly contextual in every sense, compared with Indo-European languages. The Chinese language is also known to encourage individuals to use holistic style which is associated with interdependent social orientation (DeAndrea et al. 2010; Oyserman and Lee 2008; Ross et al. 2002). However, the Uyghur-Chinese language is one kind of alphabet language which is atomic and analytic by nature, and is fit for dealing with independent social orientation and practice ("Uyghur Language." 2014). It seems that Uyghur-Chinese are more primed by language with being independent while Han-Chinese are more interdependent.

\section{Religion}

Unlike Han-Chinese who have no traditional religion and who believe in Confucianism, Uyghur-Chinese have a traditional religion. They believe in Islam now. At the beginning, they trusted Shamanism and Zoroastrianism which were considered of dualism doctrine (Xiong and Kang 2006). Religion led people to be independent, and interdependent for those who had no religion. Although there is no evidence whether the Islam religion influences independent/interdependent selfconstrual, some religions were found to be antecedent of individualism (Oyserman et al. 2002). For example, Protestant beliefs have a tendency to make people independent and this may explain why many Caucasian Americans (who are also Protestants) are considered to be the most independent compared with people from many other countries (Cohen and Hill 2007). Islam has similar roots with Jewish and Christian beliefs which may have an effect on individualism. As we all know, Han-Chinese have no traditional religion, in particular, they do not have any formal religious organization. This is seen as the opposite of American culture which includes the practice of religion for most people, many of them are Christians and Protestants. This suggests that Uyghur-Chinese who has a religion is more independent than Han-Chinese who has no religion tradition.

\section{Ecology}

Uyghur-Chinese live in a rougher habitat with hot summer and cold winter that make human demands difficult to be satisfied compared to Han-Chinese. Climatoeconomic theory posits that inhabitants of such ecology with low-income will appraise their situation as threatening and then adapt to it by relying more on ingroups to achieve their goals, which is related to collectivism (Van de Vliert 2011; Van de Vliert et al. 2013). Van de Vliert found that Xinjiang inhabited mainly by Uyghur-Chinese had higher collectivism than with other provinces where HanChinese lived (Van de Vliert et al. 2013). From a climate perspective, UyghurChinese are more interdependent than Han-Chinese are. 
Besides climate, Uyghur-Chinese and Han-Chinese have other different ecologies which were proved to have effects on independent/interdependent social orientation. Uyghur-Chinese are into herding and live in oasis environment which led them to embrace independent social behaviors and psychological tendencies, such as competition and individual decision-making and decontextualized, analytical mode of thoughts. While Han-Chinese are farmers who live on food from land which perhaps foster interdependent social behaviors and psychological tendencies such as in-group cooperation and contextualized, holistic mode of thought.

\section{Commercialization}

Uyghur-Chinese have a long history in commerce in Silk Road which is an important ancient road used for trading goods. Commercialization may foster independent self because it requires independent decision and interactions with strangers of out-groups (Henrich et al. 2010; Kitayama and Uskul 2011). In the long history, Han-Chinese had been inhibited to do business and motivated to be farmers. For many of them, peasants ranked higher than merchants in social class did (Yü 1994; Jacobs et al. 1995). Compared with their counterpart, Uyghur-Chinese may be more independent given their trade practice and experience.

Based on the antecedents mentioned above, Uyghur-Chinese lived in a hard environment wherein group solidarity was necessary for survival, and at the same time, personal success had its roots or connections in making business exchanges with out-groups or strangers. Situated model theory of culture suggests that culture is dynamically consistent due to the chronic salience of individualism and collectivism (Oyserman and Lee 2008). There are possibilities that in some situations, the independent self of Uyghur-Chinese was developed. For example, many of them are located in Silk Road and do business with out-groups or strangers, and this situation motivated them to be independent. In other situations, they are motivated to embrace their interdependent selves via group identification. For example, in custom festivals or religious activities, they interact with kinship members or other persons who have the same religious background, and so this encourages interdependence. In another study, there is indirect evidence that Arabic culture showed both more of being independent and interdependent compared with east and west counterparts (Maddux et al. 2011).

The purpose of this article was to explore cultural differences of Uyghur-Chinese and Han-Chinese on independent/interdependent self. We predicted that UyghurChinese may be both more independent via personal success and interdependent via group identification compared with Han-Chinese.

\section{Study 1}

Study 1 was designed to examine whether Uyghur-Chinese embrace independent self and interdependent self simultaneously compared with Han-Chinese and with Danish people. Although Han-Chinese samples were initially argued in literature 
review, it is better to use two control groups which include eastern and western cultures to test the hypothesis. Denmark's culture endorsed independent social orientation (Nelson and Shavitt 2002).

We just used explicit beliefs of independence and interdependence in Study 1. We predicted that Uyghur-Chinese were similar to Danish people and scored higher than Han-Chinese did for independent self and scored higher than Han-Chinese and Danish did for interdependent self.

\section{Ethic statement}

Institutional Review Board of the Institute of Psychology, Chinese Academy of Sciences approved the procedures for the experiment. It is the policy of this Review Committee to obtain written or verbal consent and participants provided verbal informed consent, recorded by the experimenter on a written log sheet. For UyghurChinese, we haven't got informed consent from his/her caretakers because all the subjects but one were over 18 years old. For this respondent who is 17 , He didn't tell us when he participated in the survey. We just knew the information when we did analysis. So we had no way to get content from his guardian. He also was undergraduate in the same university with other Uyghur-Chinese who usually took care himself and had the ability to know that the survey didn't hurt him. We also included him in analysis and IRB was told and agreed later.

\section{Participants}

Thirty-five Han-Chinese (14 males and 21 females), 35 Uyghur-Chinese (14 males and 21 females), and 16 Danish people (5 males and 11 females) participated in the study. All participants were recruited on university campuses in Beijing. Besides posters, snowball recruitment (i.e., through word of mouth) was encouraged, especially for Uyghur-Chinese participants. The age of the Han-Chinese participants varied from 18 to 21 years $(\mathrm{M}=19.09, \mathrm{SD}=1.01)$; Uyghur-Chinese ages varied from 17 to 28 years old $(\mathrm{M}=23.06, \mathrm{SD}=2.26)$; and Danish varied from 22 to 27 years $(\mathrm{M}=24.06$, $\mathrm{SD}=1.34)$. Danish participants only finished social orientation scales.

\section{Measures}

\section{Social orientation (interdependence vs. independence)}

We used Singelis (1994) Self-Construal Scale (SCS), a well-validated, 24-item measure of individual's explicit social orientation. It consisted of two subscales concerning interdependent-self (e.g., "It's important for me to maintain harmony within my group.") and independent-self (e.g., "I enjoy being unique and different from others in many respects.") with 12 items, respectively (using a seven-point scale: $1=$ "strongly disagree" to $7=$ "strongly agree"). The reliability (Cronbach's alpha) of interdependence and independence subscales in this study was 0.80 and 0.73 . 


\section{Self-esteem}

Self-esteem was assessed with the Rosenberg (1965) Self-Esteem Scale (RSES), a 10 -item measure of global, personal self-esteem. Its average reliability coefficient was greater than 0.80 (Rosenberg 1965). Responses were made on a 4-point scale ( $1=$ "very unfit" to $4=$ "very fit"). Half of the items have been formulated and scored in the reverse direction to reduce the possibility of an acquiescence response set.

All the materials for Uyghur-Chinese and Han-Chinese were in Chinese. Materials for Danish were in English.

\section{Results}

Preliminary analyses showed that Han-Chinese and Uyghur-Chinese and Danish groups were completely matched on gender, and gender had no interaction with or influence on culture, $F(2,83)=0.63, n s$. There was a significant group difference on age, $F(2,83)=89.96, p<0.001, \eta^{2}=0.56$, but age has no interaction effect with culture on dependent variables. $F(2,83)=0.51, n s$ for interdependence, and $F$ $(2,83)=0.83, n s$ for independence. Thus, we did not discuss gender and age any further.

\section{Social orientation}

We dealt with independent self and interdependent self separately. The results were summarized in Fig. 1. For the independent self, one-way ANOVA with culture as between-subject variables showed a significant main effect of culture, $F(2,83)=6.28$, $p<0.01, \eta^{2}=0.13$. Post-hoc comparisons indicated that Uyghur-Chinese $(\mathrm{M}=5.19$, $\mathrm{SD}=0.74)$ and Danish $(\mathrm{M}=5.26, \mathrm{SD}=0.72)$ were more independent than HanChinese were $(\mathrm{M}=4.65, \mathrm{SD}=0.72)$ (LSD test, $p<0.01$ for both) and there are no differences between Uyghur-Chinese and Danish (LSD test, $p>0.05$ ). For the interdependent self, one-way ANOVA with culture as between-subject variables showed a significant main effect of culture, $F(2,83)=17.60, p<0.01, \eta^{2}=0.30$. Post-hoc comparisons indicated that Uyghur-Chinese $(\mathrm{M}=5.57, \mathrm{SD}=0.70)$ were more interdependent than Han-Chinese were $(\mathrm{M}=5.17, \mathrm{SD}=0.77)$ (LSD test, $p<0.05)$ and Danish $(\mathrm{M}=4.33, \mathrm{SD}=0.48)$ (LSD test, $p<0.01)$, and Han-Chinese were more interdependent than Danish were (LSD test, $p<0.01$ ).

\section{Self-esteem}

The one-way ANOVA result for self-esteem showed that Uyghur-Chinese and HanChinese had no significant difference, $F(1,68)=0.01$, $n s$. Because the self-esteem scale, presented in the same questionnaire with SCS, included half reverse-direction items, and did not show cultural difference, it could be proof that the questionnaire is free from acquiescence bias. 


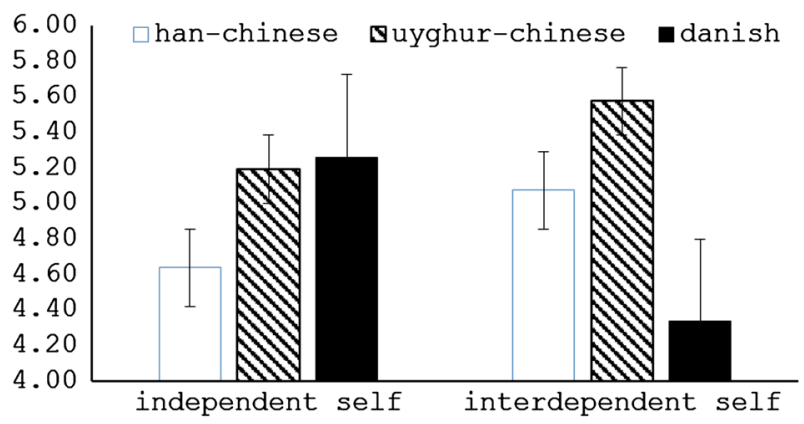

Fig. 1 Independent and interdependent self in Han-Chinese, Uyghur-Chinese and Danish. For independent self, Uyghur-Chinese are similar to Danish and more independent than Han-Chinese are. For interdependent self, Uyghur-Chinese are more interdependent than Han-Chinese and latter than Danish are. Vertical bars represent the pertinent standard errors of means

\section{Discussion}

Study 1 examined the cultural differences of social orientation and demonstrated that Uyghur-Chinese showed a unique social orientation paradigm different from the east-west paradigm. Like with Danish participants, Uyghur-Chinese embodied the spirit of independent agency. This is quite different from Han-Chinese who are less independent. At the same time, Uyghur-Chinese emphasize interdependent agency and were more interdependent compared with Han-Chinese and Danish. It seems that Uyghur-Chinese put equal weights on personal achievement and social harmony simultaneously. In Study 1, only explicit measurement was used which may be confounded with limitations of self-report methods. In Study 2, we examined the Uyghur-Chinese and Han-Chinese differences by explicit and implicit measurements of independent/interdependent self.

\section{Study 2}

For the second study, we mainly explored both explicit and implicit psychological tendency differences between Han-Chinese and Uyghur-Chinese. A growing body of evidence show that various aspects of explicit and implicit independence and interdependence differentiate between eastern and western cultures. On the one hand, eastern culture is more likely to show situational attribution and holistic thinking style, and socially engaging emotion than western counterpart will show. On the other hand, western culture is more like to show dispositional attribution and relational mobility, and socially disengaging emotion than eastern culture will show. Comparing Uyghur-Chinese and Han-Chinese, if Uyghur-Chinese are both more independent and interdependent than Han-Chinese are explicitly by SCS, it is a reasonable inference that the differences can be found by other explicit measurement and even implicit measurement. 
Cognitive tendencies of independence and interdependence

Many studies have found that western culture has the tendency to infer that another person's behavior is caused by the person's inner characteristics such as preferences and attitudes whereas eastern culture is prone to infer that a person's behavior is caused by situational factors. Kitayama found that compared with USA and Germany, Britain and Japan showed a less dispositional bias (Kitayama et al. 2009). We predict that Uyghur-Chinese will score higher than Han-Chinese on both situational and dispositional attributions.

Emotional tendencies of independence and interdependence

Emotions related with independent/interdependent self are socially disengaging/ engaging emotions. Socially engaging emotions, such as respect, are derived from social interdependence and relationally embedded in the nature of self; socially disengaging emotions, such as pride, are grounded on independence and autonomy of self and its separateness from others in a relationship (Kitayama et al. 2006).

Cross-cultural studies have found that for independent cultures, people might experience more socially disengaging emotions; and for interdependent cultures, people experience more socially engaging emotions (Kitayama et al. 2009). We predict that Uyghur-Chinese will score higher than Han-Chinese will on both socially engaging and disengaging emotions.

\section{Holism}

Nisbett and his colleagues found that compared with western culture, east-Asian showed holistic thinking styles that emphasize paying more attention to context and interactionism on causality inference and cyclic change on perception of change and Naïve Dialecticism on contradiction (Nisbett et al. 2001; Spencer-Rodgers et al. 2010). We predict that Uyghur-Chinese will score higher than Han-Chinese will on holism.

\section{Relational mobility}

As one social-ecological factor, relational mobility refers to the number of opportunities people have to select new relationship partners in a given society or social context. A variety of studies suggest that relational mobility is higher in USA than in east Asia (Yuki et al. 2013). We predict that Uyghur-Chinese will score higher than Han-Chinese will on relational mobility.

Another question of Study 2 was concerned with the psychological mechanisms of Uyghur-Chinese and Han-Chinese differences in psychological tendencies. Social orientation hypothesis suggests that independent/interdependent social orientation differences caused cultural differences in cognition other than social orientation (Varnum et al. 2010). Specifically, we hypothesized that the construal of independent self and interdependent self drives Uyghur-Chinese and Han-Chinese 
differences on emotion and attribution, and holism and relational mobility. The second goal of the Study 2 was to provide a formal test of this meditation hypothesis. We predict that independent self-construal mediates the relationship between culture (Uyghur-Chinese and Han-Chinese) and socially disengaging emotion and dispositional attribution and relational mobility, and that interdependent self-construal mediates the relationship between culture (Uyghur-Chinese and Han-Chinese) and socially engaging emotion and situational attribution and holism.

\section{Ethic statement}

Institutional Review Board of the Institute of Psychology, Chinese Academy of Sciences approved the procedures for the experiment. It is the policy of this Review Committee to obtain written or verbal consent and participants provided verbal informed consent, recorded by the experimenter on a written log sheet. For UyghurChinese, we have got informed consent from his/her caretakers.

\section{Participants}

We initiated participant recruitment in two cities: Beijing and Urumqi. Beijing is an originally Han-Chinese-inhabited city, while Urumqi is a city where UyghurChinese originally lived. We obtained 39 Han-Chinese and 39 Uyghur-Chinese participants in Beijing; and 91 Han-Chinese and 91 Uyghur-Chinese participants in Urumqi. The 91 Han-Chinese participants from Urumqi were born there and have lived there most of their lives. The 39 Uyghur-Chinese from Beijing lived in Beijing for 2-3 years, but were born in Urumqi and lived in Urumqi most of their lives. This way, the cultural differences could illustrate evidently the effect of cultural contexts.

The ages of the 130 Han-Chinese students (45 males and 85 females) varied from 15 to 25 years $(\mathrm{M}=18.61, \mathrm{SD}=2.04)$. The ages of the 130 Uyghur-Chinese students (53 males and 77 females) varied from 15 to 24 years $(M=18.98$, $\mathrm{SD}=2.07)$.

\section{Measures}

All the instruments used in Study 1 were preserved in the Study 2 questionnaire. We also added two cultural tasks (Kitayama et al. 2006) and two other scales to measure implicit psychological tendency.

\section{Dispositional versus situational bias in attribution}

Participants were presented with four vignettes. In two of the vignettes, the protagonist engaged in a socially desirable behavior (e.g., a baseball player holding free baseball camps during his vacation), and in the remaining two, the protagonist engaged in a socially undesirable behavior (e.g., a surgeon covering up a major medical mistake). Participants were asked to read and indicate the extent to which they agreed with (a) features of the protagonist such as his or her character, how his 
or her attitude or temperament influenced his or her behavior (dispositional attribution judgment); (b) features of the environment that surrounded the protagonist such as the atmosphere, social norms, or other contextual factors that may have influenced his or her behavior (situational attribution judgment); (c) the possibility that the protagonist would have acted differently if his or her dispositional features had been different (counterfactual dispositional judgment); and (d) the possibility that the protagonist would have acted differently if features of his or her environment had been different (counterfactual situational judgment). Seven-point scales were used ( 1 = "strongly disagree" to $7=$ "strongly agree"). We obtained the means for the two dispositional items and for the two situational items. The name of the protagonist and the place were replaced with common names of Han-Chinese and Uyghur-Chinese separately.

Experience of socially disengaging versus socially engaging emotions

We administered the Implicit Social Orientation Questionnaire (ISOQ; Kitayama and Park 2007), in which participants were asked to recall 10 mundane social situations and to report the extent to which they experienced a variety of different emotions during the events. Socially disengaging emotions are predicated on achieving/failing at personal goals (e.g., pride, anger, contempt) and suggest cultural independence; socially engaging emotions are related to success/failure at interpersonal goals (e.g., friendly feelings, guilt) and suggest cultural interdependence. Response options for each emotion ranged from 1 (not at all) to 6 (very strongly). For each participant, we first determined the perceived valence of each of the 10 situations. For each situation, the rating of the general negative emotion (unhappy) was subtracted from the average rating of the three general positive emotions (elated, happy, and calm). If the situation was positive (i.e., if the difference was positive), the average rating of disengaging positive emotions (e.g., pride in self) and the average rating of engaging positive emotions (e.g., friendly feelings) were obtained. Conversely, if the situation was negative (i.e., if the difference was negative), the corresponding average ratings were obtained for the disengaging negative emotions (e.g., anger) and the engaging negative emotions (e. g., shame). We then averaged the index across the 10 situations to yield an aggregate measure of the propensity to experience disengaging emotions and another aggregate measure of the propensity to experience engaging emotions.

\section{Holism}

We used the Analysis-Holism Scale (AHS, Incheol Choi et al. 2007) to measure holistic thinking tendency. The scale consists of 24 items (e.g., "It is more important to pay attention to the whole context rather than the details.") with seven-point Likert-type rating ( $1=$ "strongly disagree" to $7=$ "strongly agree"). Five of the items were formulated in the reverse direction to reduce the possibility of acquiescence bias. The higher score on AHS indicates a stronger holistic style of thinking. The reliability coefficient in this study is 0.88 . 


\section{Relational mobility}

We adopted Relational Mobility Scale (RMS, Yuki et al. 2007). To avoid issues such as cultural differences in self-enhancement (e.g., Heine and Hamamura 2007), participants were asked to report their perceptions of the levels of relational mobility for people in general in their surrounding society, rather than for themselves personally. There are 12 items of the relational mobility scale including "In most circumstances, it is easy for people to make new acquaintances" and "Even if people are not satisfied with their current relationships, they often have no choice but to stay with them (reversed)". Half of the items were in reverse direction. Responses were made using a seven-point Likert-type scale $(1=$ "strongly disagree" to $7=$ "strongly agree"). The reliability coefficient in this study is 0.86 .

\section{Procedure}

Participants filled out the scales and completed a short demographic questionnaire on paper. All materials were translated and back-translated from English into Chinese by two native speakers to ensure linguistic equivalence. All the materials for Uyghur-Chinese and Han-Chinese were in Chinese. The questionnaire took approximately $30 \mathrm{~min}$ to complete and each participant received $20 \mathrm{RMB}$.

\section{Results}

Social orientation (interdependence vs. independence)

The mean interdependence and independence scores are summarized in Table 1. Based on the results of Study 1, we dealt with independent self and interdependent self separately. For the interdependent self, a $2 \times 2$ ANOVA with culture and city as between-subject factors showed a significant main effect of culture and city. With regard to culture, Uyghur-Chinese $(\mathrm{M}=5.66, \mathrm{SD}=0.70)$ were more interdependent than Han-Chinese were $(\mathrm{M}=5.24, \mathrm{SD}=0.73), F(1,258)=20.85, p=0.00, \eta^{2}=0.08$. With regard to city, Urumqi $(\mathrm{M}=5.52, \mathrm{SD}=0.08)$ was more interdependent than Beijing was $(\mathrm{M}=5.28, \mathrm{SD}=0.05), F(1,258)=20.85, p=0.00, \eta^{2}=0.08$. For the independent self, a $2 \times 2$ ANOVA with culture and city as between-subject factors showed a significant main effect of culture and city. With regard to culture, UyghurChinese $(\mathrm{M}=5.23, \mathrm{SD}=0.74)$ were more independent than Han-Chinese were $(\mathrm{M}=4.51, \mathrm{SD}=0.74), F(1,258)=49.36, p=0.00, \eta^{2}=0.16$. With regard to city, Urumqi $(\mathrm{M}=5.07, \mathrm{SD}=0.08)$ was more independent than Beijing was $(\mathrm{M}=4.71$, $\mathrm{SD}=0.05), F(1,258)=11.47, p=0.00, \eta^{2}=0.04$.

Dispositional versus situational attribution bias

The mean dispositional and situational scores are summarized in Table 1. We dealt with dispositional and situational attributions separately. For dispositional 
Table 1 Descriptive statistics (Mean \pm Sd) of independent and interdependent variables

\begin{tabular}{lcc}
\hline & Han-Chinese & Uyghur-Chinese \\
\hline 1. Interdependent-self & $5.24 \pm 0.73$ & $5.66 \pm 0.70$ \\
2. Independent-self & $4.56 \pm 0.75$ & $5.36 \pm 0.85$ \\
3. Situational attribution & $4.60 \pm 0.76$ & $5.39 \pm 0.99$ \\
4. Dispositional attribution & $4.90 \pm 0.79$ & $5.49 \pm 0.93$ \\
5. Socially engaging emotion & $2.82 \pm 0.78$ & $3.58 \pm 0.95$ \\
6. Socially disengaging emotion & $2.53 \pm 0.77$ & $3.62 \pm 0.98$ \\
7. Relational mobility & $4.23 \pm 0.63$ & $4.93 \pm 1.11$ \\
8. Holism & $4.72 \pm 0.72$ & $5.15 \pm 0.91$ \\
\hline
\end{tabular}

attribution, a $2 \times 2$ ANOVA with culture and city as between-subject factors showed a significant main effect of culture and city. For culture, Uyghur-Chinese $(\mathrm{M}=5.50, \mathrm{SD}=0.93)$ scored higher than Han-Chinese did $(\mathrm{M}=4.90, \mathrm{SD}=0.79)$, $F(1,258)=18.58, p=0.00, \eta^{2}=0.07$. For city, Urumqi $(\mathrm{M}=5.31, \mathrm{SD}=0.94)$ scored higher than Beijing did $(\mathrm{M}=4.92, \mathrm{SD}=0.78), F(1,258)=11.86, p=0.00$, $\eta^{2}=0.04$. There was interaction effect between city and culture. The cultural differences of Uyghur-Chinese and Han-Chinese were significant only in Urumqi. $F$ $(1,258)=5.68, p=0.02, \eta^{2}=0.02$. For situational attribution, a $2 \times 2$ ANOVA with culture and city as between-subject factors showed a significant main effect of culture and city. For culture, Uyghur-Chinese $(M=5.39, \mathrm{SD}=0.99)$ were more interdependent than Han-Chinese were $(\mathrm{M}=4.60, \mathrm{SD}=0.76), F(1,258)=31.93$, $p=0.00, \eta^{2}=0.11$. For city, Urumqi $(\mathrm{M}=5.14, \mathrm{SD}=1.03)$ scored higher than Beijing did $(\mathrm{M}=4.64, \mathrm{SD}=0.70), F(1,258)=18.50, p=0.00, \eta^{2}=0.07$. There was interaction effect between city and culture. The cultural differences of UyghurChinese and Han-Chinese were significant only in Urumqi. $F(1,258)=10.27$, $p=0.02, \eta^{2}=0.04$.

Experience of socially disengaging versus socially engaging emotions

The mean socially disengaging and engaging scores are summarized in Table 1. We dealt with disengaging and engaging emotions separately. For socially disengaging emotion, a $2 \times 2$ ANOVA with culture and city as between-subjects factors showed a significant main effect of culture and city. For culture, Uyghur-Chinese $(\mathrm{M}=3.51, \mathrm{SD}=0.98)$ scored higher than Han-Chinese did $(\mathrm{M}=2.36, \mathrm{SD}=0.77)$, $F(1,258)=106.00, p=0.00, \eta^{2}=0.29$. For city, Urumqi $(\mathrm{M}=3.28, \mathrm{SD}=1.00)$ scored higher than Beijing did $(\mathrm{M}=2.59, \mathrm{SD}=0.93), F(1,258)=39.50, p=0.00$, $\eta^{2}=0.13$. For socially engaging emotion, a $2 \times 2$ ANOVA with culture and city as between-subject factors showed a significant main effect of culture and city. For culture, Uyghur-Chinese $(\mathrm{M}=3.50, \mathrm{SD}=0.95)$ scored higher than Han-Chinese $\operatorname{did}(\mathrm{M}=2.71, \mathrm{SD}=0.86), F(1,258)=48.36, p=0.00, \eta^{2}=0.16$. For city, Urumqi $(\mathrm{M}=3.35, \mathrm{SD}=0.08)$ scored higher than Beijing did $(\mathrm{M}=2.85$, $\mathrm{SD}=0.05), F(1,258)=19.10, p=0.00, \eta^{2}=0.07$. 


\section{Holism}

The mean holism score is summarized in Table 1 . A $2 \times 2$ ANOVA with culture and city as between-subject factors showed a significant main effect of culture and city. For culture, Uyghur-Chinese $(\mathrm{M}=5.04, \mathrm{SD}=0.90)$ scored higher than HanChinese did $(\mathrm{M}=4.73, \mathrm{SD}=0.72), F(1,258)=8.18, p=0.01, \eta^{2}=0.03$. For city, Urumqi $(\mathrm{M}=5.02, \mathrm{SD}=0.96)$ scored higher than Beijing did $(\mathrm{M}=4.74, \mathrm{SD}=0$. $43), F(1,258)=6.73, p=0.00, \eta^{2}=0.03$. There was interaction effect between city and culture. The cultural differences of Uyghur-Chinese and Han-Chinese were significant only in Urumqi, $F(1,258)=7.44, p=0.01, \eta^{2}=0.03$.

\section{Relational mobility}

The relational mobility score is summarized in Table 1 . A $2 \times 2$ ANOVA with culture and city as between-subject factors showed a significant main effect of culture. For culture, Uyghur-Chinese $(\mathrm{M}=4.77, \mathrm{SD}=1.11)$ scored higher than Han-Chinese did $(\mathrm{M}=4.30, \mathrm{SD}=0.62), F(1,258)=16.74, p=0.00, \eta^{2}=0.06$. There was interaction effect between city and culture. The cultural differences of Uyghur-Chinese and Han-Chinese were only significant in Urumqi. $F(1$, 258) $=26.29, p=0.01, \eta^{2}=0.09$.

\section{Self-esteem}

A $2 \times 2$ ANOVA with culture and city as between-subject factors showed a significant main effect of city. Culture has no main effect on self-esteem. For city, Uyghur-Chinese $(\mathrm{M}=2.81, \mathrm{SD}=0.41)$ scored lower than Han-Chinese did $(\mathrm{M}=3.00, \mathrm{SD}=0.41), F(1,258)=11.98, p=0.00, \eta^{2}=0.05$. There was interaction effect between city and culture. The city differences of Uyghur-Chinese and Han-Chinese were significant only in Beijing, $F(1,258)=3.95, p=0.05$, $\eta^{2}=0.02$. Along with the AHS and RMS, these three scales including reversed items could reduce the questionnaire's acquiescence bias.

\section{Mediation mechanism}

We subsequently examined whether independent/interdependent self-construal mediated the relationship between culture and each of the psychological tendencies measured in this study by performing a series of multiple regression analyses.

As with Figs. 2 and 3, in each case, the conditions for establishing mediation according to Shrout and Bolger (2002) were met (Shrout and Bolger 2002). Specifically, culture was related to interdependent-self and independent-self, and interdependent-self was related to situational attribution, socially engaging emotion, and holism; independent-self was related to dispositional attribution, socially disengaging emotion, and relational mobility. Importantly, multiple regression 

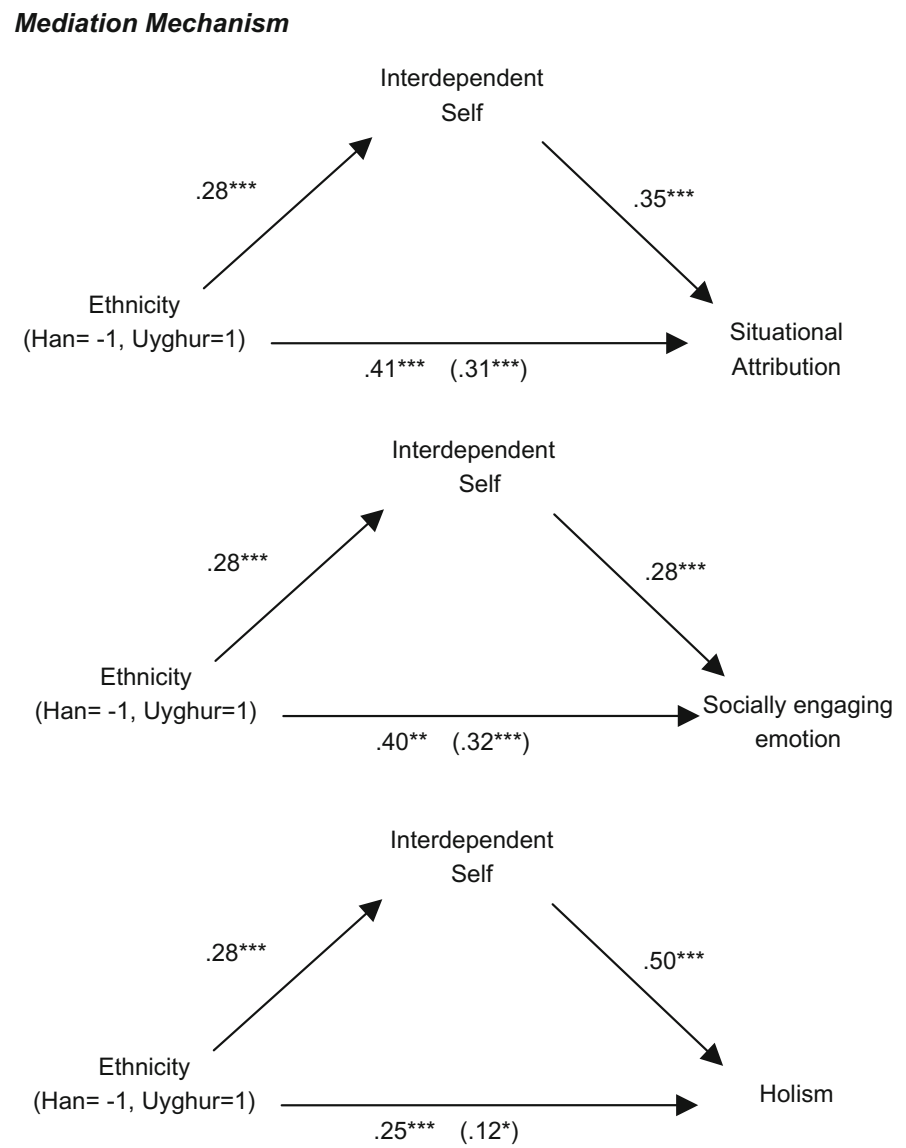

Fig. 2 Standardized betas from a path analysis examining the role that interdependent-self plays in mediating the effects of culture on a situational attribution (Panel A), b socially engaging emotion (Panel B), and $\mathbf{c}$ holism (Panel C). Note. The standardized coefficients in parentheses show the relationship between culture and the dependent variables after controlling for interdependent-self. $* * * p<0.001$; ${ }^{*} p<0.05$

indicated that controlling for social orientation (interdependent-self or independentself) significantly attenuated the relationship between culture (Uyghur-Chinese and Han-Chinese) and the psychological tendency variables. Sobel tests confirmed the results, indicating that culture effects were mediated by interdependent-self (situational attribution: Sobel $=3.11, p<0.01$; socially engaging emotion: Sobel $=2.80, p<0.01$; holism: Sobel $=3.32, p<0.001)$, as were mediated by independent-self (dispositional attribution: Sobel $=4.37, p<0.001$; socially disengaging emotion: Sobel $=4.42, p<0.001$; relational mobility: Sobel $=4.51$, $p<0.001)$. 

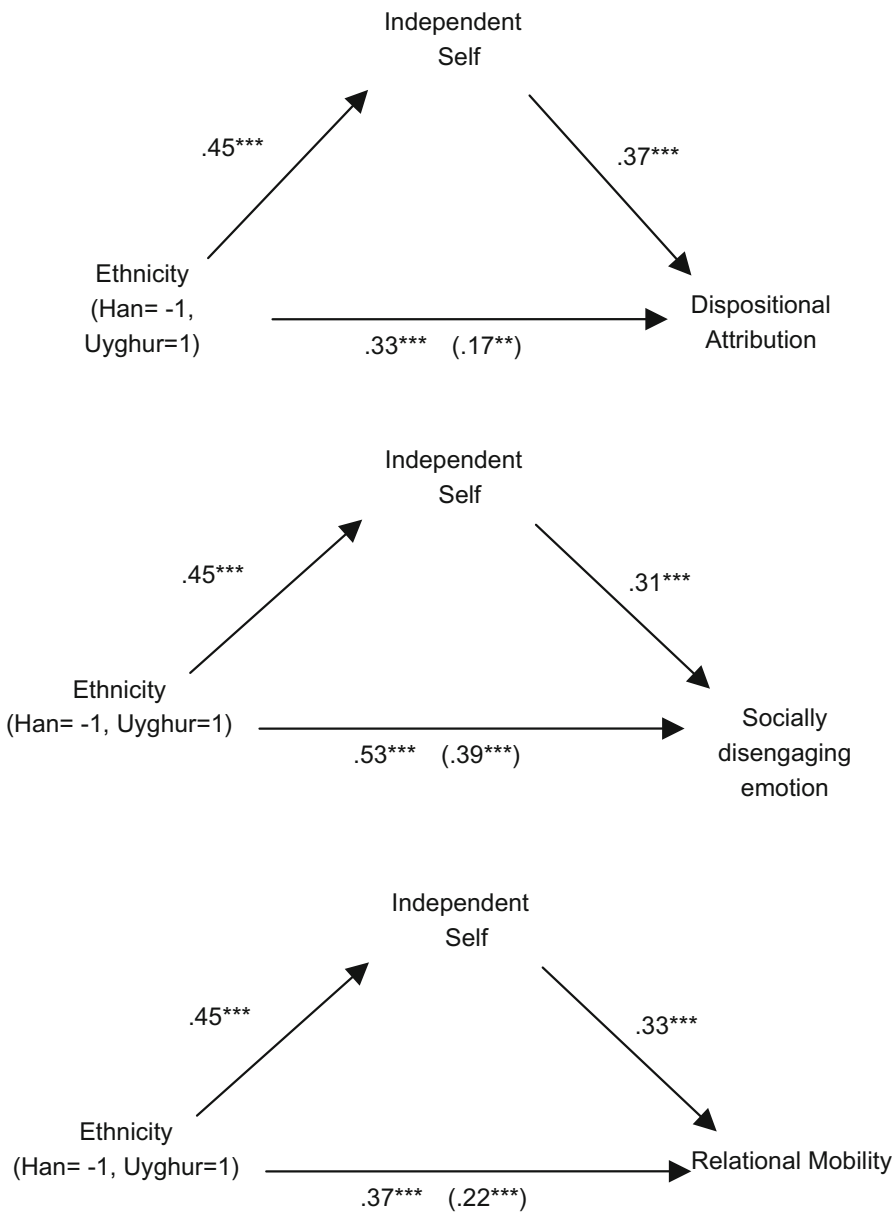

Fig. 3 Standardized betas from a path analysis examining the role that independent-self plays in mediating the effects of ethnicity on a dispositional attribution (Panel A), b socially disengaging emotion (Panel b), and c relational mobility (Panel C). Note. The standardized coefficients in parentheses show the relationship between ethnicity and the dependent variables after controlling for independent-self. $* * * p<0.001$; ** $p<0.01$

\section{Discussion and conclusion}

In the two studies, we predicted and found that Uyghur-Chinese were more independent and interdependent compared with Han-Chinese. On the one hand, Uyghur-Chinese showed more independent social orientation than Han-Chinese did, so did dispositional attribution, socially engaging emotions experienced in the last month, and relational mobility. On the other hand, Uyghur-Chinese showed more interdependent social orientation than Han-Chinese did, so did situational attribution and socially engaging emotion and holistic style. In addition, there were two control groups which Han-Chinese represented interdependent self culture and 
Danish independent self culture in Study 1. Uyghur-Chinese was similar to Danish on independent self and scored higher than Han-Chinese did on interdependent self. Furthermore, these differences in self-views would partially mediate cultural differences on the psychological tendencies that we observed.

Our research extends previous findings on cultural differences of self-construal theory in two ways. As the response of calling for more research from expansion of samples and populations which is beyond east-west paradigm, this study is one of the first to examine psychological characteristics of individuals in Uyghur-Chinese culture, and the first to measure the implicit cultural orientations of individuals in Uyghur-Chinese. Previous research in cultural psychology has tended to prescribe and classify countries and regions into either independent or interdependent (Kitayama and Uskul 2011). In this domain, Chinese (actually Han-Chinese) belong to the interdependent culture. Like USA, China is also a multi-ethnic and multicultural nations with many within-nation variances that cannot be taken for granted as having the same self-construal. Uyghur-Chinese see themselves differently from Han-Chinese. We also found that Uyghur-Chinese showed a mixed picture, that of being more independent and interdependent compared with their counterpart. It cannot be fit into the eastern-western paradigm. Maddux found that Arabian culture also showed a unique pattern which is more independent and interdependent compared with its eastern and western counterparts (Maddux et al. 2011). Our findings give support to Maddux that there may be other patterns of self-construal besides the east-west paradigm.

There are several limitations to be considered in evaluating this research. First, acquiescence bias for measurements of independent/interdependent self may exist, especially for Singelis's SCS which has no reverse items to control acquiescence bias (Church et al. 2012). However, in Study 1, self-esteem, which has reverse items, was measured at the same time and showed no differences between UyghurChinese and Han-Chinese. In Study 2, holism and relational mobility also have reverse items. Both of these measurements can effectively reduce the acquiescence bias to the extent that the Uyghur-Chinese and Han-Chinese differences on selfconstrual are stable. Second, note that there are many measurements of independent/ interdependent self. Furthermore, some measurements assumed that independent/ interdependent self was opposite polar of uni-dimension such as self-inflation. We used some of them in this research. It is unknown that other measures of independent/interdependent self show similar results between Uyghur-Chinese and Han-Chinese, especially for those uni-dimensional measurement. As we mentioned, Uyghur-Chinese will manifest more independence in some situations and more interdependence in other situations. To expand our understanding of UyghurChinese, it is worth exploring in which situations Uyghur-Chinese will be more independent/interdependent as part of their culture. Third, there are many distal and proximal antecedents that may lead to Uyghur-Han differences on self-construal and for which, their effects were compounded together. Future research should use experimental methods to examine their effects individually. For example, we can prime Uyghur-Chinese participants or have them ready by showing a picture of an oasis to gauge whether ecological environment would lead to a manifestation of independent self or not. Fourth, materials were in Han-Chinese language that is not 
native for Uyghur-Chinese, although all participants are fluent in Han-Chinese. It is possible that the Han-Chinese language and associated eastern concepts could have primed Uyghur-Chinese to respond as more interdependent than they typically are. However, we believe that this effect is not important: Uyghur-Chinese are more interdependent on the measurement of situational attribution, but they are also more independent on the measurement of dispositional attribution, a pattern of results which suggests that the Han-Chinese language medium did not overly bias the results in an interdependent direction.

Although cultural psychology has been around the past two decades, psychologists know little about the social orientation of other cultures besides western and eastern countries. It is suggested that Uyghur-Chinese provide an opportunity to know and see the whole picture of cross-culture differences on independent/ interdependent self all over the world.

Acknowledgments We are grateful to Michael Varnum for providing helpful comments on earlier versions of this paper. This research was supported by Ministry of Science and Technology of China (2009FY110100) and emergy project of Institute of Psychology, Chinese Academy of Sciences.

\section{References}

Church, A. T., Willmore, S. L., Anderson, A. T., Ochiai, M., Porter, N., Mateo, N. J., et al. (2012). Cultural differences in implicit theories and self-perceptions of traitedness: Replication and extension with alternative measurement formats and cultural dimensions. Journal of Cross-Cultural Psychology, 43(8), 1268-1296. doi:10.1177/0022022111428514.

Choi, I., Koo, M., \& Choi, J. A. (2007). Individual differences in analytic versus holistic thinking. Personality and Social Psychology Bulletin, 33(5), 691-705. doi:10.1177/0146167206298568.

Cohen, A. B., \& Hill, P. C. (2007). Religion as culture: Religious individualism and collectivism among American catholics, jews, and protestants. Journal of Personality, 75(4), 709-742. doi: 10.1111/j.1467-6494.2007.00454.x.

Cross, S. E., Hardin, E. E., \& Gercek-Swing, B. (2011). The what, how, why, and where of self-construal. Personality and Social Psychology Review, 15(2), 142-179.

DeAndrea, D. C., Shaw, A. S., \& Levine, T. R. (2010). Online language: The role of culture in selfexpression and self-construal on facebook. Journal of Language and Social Psychology, 29(4), 425442. doi:10.1177/0261927x10377989.

Heine, S. J. (2010). Cultural psychology. In S. T. Fiske, D. T. Gilbert \& G. Lindzey (Eds.), Handbook of social psychology. Hoboken: Wiley.

Heine, S. J., \& Hamamura, T. (2007). In search of East Asian self-enhancement. Personality and Social Psychology Review, 11(1), 4-27.

Henrich, J., Heine, S. J., \& Norenzayan, A. (2010). The weirdest people in the world?. Behav Brain Sci, 33(2-3), 61-83; discussion 83-135. doi: 10.1017/s0140525x0999152x.

Kitayama, S., \& Park, H. (2007). Cultural shaping of self, emotion, and well-being: How does it work? Social and Personality Psychology Compass, 1(1), 202-222.

Kitayama, S., Ishii, K., Imada, T., Takemura, K., \& Ramaswamy, J. (2006a). Voluntary settlement and the spirit of independence: Evidence from Japan's "northern frontier". Journal of Personality and Social Psychology, 91(3), 369-384. doi:10.1037/0022-3514.91.3.369.

Kitayama, S., Mesquita, B., \& Karasawa, M. (2006b). Cultural affordances and emotional experience: Socially engaging and disengaging emotions in Japan and the United States. Journal of Personality and Social Psychology, 91(5), 890-903. doi:10.1037/0022-3514.91.5.890.

Kitayama, S., Park, H., Sevincer, A. T., Karasawa, M., \& Uskul, A. K. (2009). A cultural task analysis of implicit independence: comparing North America, Western Europe, and East Asia. Journal of Personality and Social Psychology, 97(2), 236-255. doi:10.1037/a0015999. 
Kitayama, S., \& Uskul, A. K. (2011). Culture, mind, and the brain: Current evidence and future directions. Annual Review of Psychology, 62, 419-449. doi:10.1146/annurev-psych-120709-145357.

Knight, N., \& Nisbett, R. E. (2007). Culture, class and cognition: Evidence from Italy. Journal of Cognition and Culture, 7(3-4), 3-4.

Maddux, W., San Martin, A., Sinaceur, M., \& Kitayama, S. (2011). In the middle between east and west: Implicit cultural orientations in Saudi Arabia. Paper presented at the 24rd Annual International Association of Conflict Management Conference, Istanbul, Turkey.

Markus, H. R., \& Kitayama, S. (1991). Culture and the self-implications for cognition, emotionand motivation and motivation. Psychological Review, 98(2), 224-253. doi:10.1037//0033-295x. 98.2.224.

Nelson, M. R., \& Shavitt, S. (2002). Horizontal and vertical individualism and achievement values: A multimethod examination of Denmark and the United States. Journal of Cross-Cultural Psychology, 33(5), 439-458. doi:10.1177/0022022102033005001.

Nisbett, R. E., Peng, K. P., Choi, I., \& Norenzayan, A. (2001). Culture and systems of thought: Holistic versus analytic cognition. Psychological Review, 108(2), 291-310.

Oyserman, D., Coon, H. M., \& Kemmelmeier, M. (2002). Rethinking individualism and collectivism: Evaluation of theoretical assumptions and meta-analyses. Psychological Bulletin, 128(1), 3-72. doi: 10.1037//0033-2909.128.1.3.

Oyserman, D., \& Lee, S. W. S. (2008). Does culture influence what and how we think? Effects of priming individualism and collectivism. Psychological Bulletin, 134(2), 311-342. doi:10.1037/0033-2909. 134.2.311.

Rosenberg, M. (1965). Society and adolescent self-image. Princeton, NJ: Princeton University.

Ross, M., Xun, W. Q. E., \& Wilson, A. E. (2002). Language and the bicultural self. Personality and Social Psychology Bulletin, 28(8), 1040-1050. doi:10.1177/01461672022811003.

Shrout, P. E., \& Bolger, N. (2002). Mediation in experimental and nonexperimental studies: New procedures and recommendations. Psychological Methods, 7(4), 422-445. doi:10.1037//1082-989x. 7.4.422.

Singelis, T. M. (1994). The measurement of independent and interdependent self-construals. Personality and Social Psychology Bulletin, 20(5), 580-591.

Spencer-Rodgers, J., Williams, M. J., \& Peng, K. P. (2010). Cultural differences in expectations of change and tolerance for contradiction: A decade of empirical research. Personality and Social Psychology Review, 14(3), 296-312. doi:10.1177/1088868310362982.

Triandis, H. C. (1989). The self and social behavior in differing cultural contexts. Psychological review, 96(3), 506.

Triandis, H. C. (2001). Individualism-collectivism and personality. Journal of Personality, 69(6), 907924. doi:10.1111/1467-6494.696169.

Uskul, A. K., Kitayama, S., \& Nisbett, R. E. (2008). Ecocultural basis of cognition: Farmers and fishermen are more holistic than herders. Proceedings of the National Academy of Sciences, 105(25), 8552-8556.

Uyghur Language. (2014). Retrieved March 10, 2014, from http://en.wikipedia.org/wiki/Uyghur_ language.

Jacobs, L., Guopei, G., \& Herbig, P. (1995). Confucian roots in China: a force for today's business. Management Decision, 33(10), 29-34.

Van de Vliert, E. (2011). Climato-Economic origins of variation in ingroup favoritism. Journal of CrossCultural Psychology, 42(3), 494-515. doi:10.1177/0022022110381120.

Van de Vliert, E., Yang, H., Wang, Y., \& Ren, X.-P. (2013). Climato-economic imprints on Chinese collectivism. Journal of Cross-Cultural Psychology, 44(4), 589-605.

Varnum, M. E. W., Grossmann, I., Kitayama, S., \& Nisbett, R. E. (2010). The Origin of cultural differences in cognition: The social orientation hypothesis. Current Directions in Psychological Science, 19(1), 9-13. doi:10.1177/0963721409359301.

Xiong, K. X., \& Kang, J. Z. (2006). A survey of the uyghur ethic concepts. [维吾尔族伦理思想概述]. Journal of Xinjiang Normal University (Social Sciences), 27(01), 5-12.

Yü, Y. S. (1994). Intellectual breakthroughs in the T'ang-Sung transition. In A. H. P. a. Y.-s. Y. Willard J. Peterson (Ed.), The power of culture (pp. 158-171). Hong Kong: The Chinese University of Hong Kong Press.

Yuki, M., Sato, K., Takemura, K., \& Oishi, S. (2013). Social ecology moderates the association between self-esteem and happiness. Journal of Experimental Social Psychology, 49(4), 741-746. doi: 10.1016/j.jesp.2013.02.006. 
Yuki, M., Schug, J., Horikawa, H., Takemura, K., Sato, K., Yokota, K., \& Kamaya, K. (2007). Development of a scale to measure perceptions of relational mobility in society. CERSS Working Paper 75, Center for Experimental Research in Social Sciences, Hokkaido University.

Zhu, Y., Zhang, L., Fan, J., \& Han, S. H. (2007). Neural basis of cultural influence on self-representation. Neuroimage, 34(3), 1310-1316. doi:10.1016/j.neuroimage.2006.07.047. 